\title{
SINKRETISME DALAM AGAMA HINDU DAN BUDDHA DI BALI
}

\author{
Oleh : \\ I Nyoman Kiriana \\ Dosen Fakultas Dharma Acarya IHDN Denpasar
}

\begin{abstract}
In religious life, at first the existence of Hindu and Buddhist very harmonious and contradictory in their home country, namely India. But the two religions in Indosesia seem very harmonious, especially in the era of the Majapahit kingdom. Moreover, the existence of Hinduism and Buddhism in Bali very harmony and even complement each other in practice and spiritual order. Buddhism is very much a substance similar to the teachings of Hinduism. In some Hindu literature was found a lot in common with the essence of Buddhism, and vice versa. Very often found literature-literature that reflects the harmony of both religions, among others: Lontar Siwagama, Kekawin Mahabharata, Ramayana Kekawin, Kekawin Arjuna Wiwaha, Kekawin Bharata Yudha and Kekawin Sutasoma, Sanghyang Kamahayanikan, Bubugsah Gagakaking and so on. By looking at it as if the two religions fused in practice in Bali, especially in the implementation of religious activities such as the ritual tawur agung in connection with the celebration of Nyepi Saka as the New Year.
\end{abstract}

Keywords: Moska, Nirvana, Reincarnation, Karmaphala

\section{Pendahuluan}

Pulau Bali ini memiliki sejarah yang panjang dalam pembangunan kebudayaannya, sehingga pulau Bali dinyatakan memiliki "tradisi besar". Oleh karena itu, Bali mengembangkan pariwisata budaya, karena kebudayaan merupakan paling potensial bagi kehidupan masyarakatnya. Kebudayaan yang ada di Bali sangat unik dan merakyat yaitu menyatunya antara agama, kebudayaan, dan adat yang harmonis, yang diekspresikan dalam kehidupan seni dan etika yang bernuansa religius oleh masyarakat Hindu di Bali.

Perkembangan agama Hindu di Bali sangat bervariasi "dalam tata pelaksanaannya" dengan agama Hindu di India, walaupun India merupakan tempat asalnya. Perbedaan ini disebabkan oleh karena agama Hindu dalam perkembanganya selalu berpadu dengan budaya-budaya lokal, teologi lokal, dan adat lokal untuk mengembangkan dirinya "sejauh budaya, teologi, dan adat tersebut tidak bertentangan dengan ajaran agama Hindu, akan tetapi apabila ada yang bertentangan, akan diusahakan menjadi serasi". Sehingga agama Hindu dinyatakan sebagai agama yang tidak mempunyai bentuk dan selalu merupakan suatu himpunan dari unsur-unsur yang tidak sama dan tidak tetap. Agama Hindu diibaratkan sebuah "bola salju" yang selalu mengelinding dan semakin besar, karena menghisap sebagian besar yang dilaluinya, akan tetapi memiliki esensi dan azas yang sama. Akan tetapi hanya penyebutan dan tata pelaksanaan hidup beragama yang berbeda. Oleh karena itu, agama Hindu dirumuskan sebagai agama yang 
tidak memiliki suatu pengakuan iman yang dapat dirumuskan dengan jelas, dan disepakati oleh semua pengikutnya.

Dalam kehidupan masyarakat Hindu di Bali, antara agama Hindu dan Buddha ditempatkan dalam kedudukan yang sejajar, tidak ada yang lebih tinggi dan lebih rendah. Ini terbukti dari pengakuan para pendeta di Bali, bahwa para pendeta Siva tidak akan sempurna jika tidak mengetahui ajaran agama Buddha, dan sebaliknya pendeta Buddha juga mengakui tidak akan sempurna jika tidak mengetahui ajaran Siva. Air suci "tirtha Buddha" dari pendeta Buddha dipakai oleh penganut Siva untuk penyucian roh orang yang meninggal, dan sebaliknya air suci pendeta Siva dipakai oleh penganut Buddha untuk tujuan yang sama.

Dengan mengutip Astawa (Suamba, 2007:142) bahwa sejumlah prasasti Bali Kuna menyebutkan pernyataan penghormatan "namasiwaya namobuddhaya". Catatan Goris (1968:4) tentang sembilan sekte yang telah berkembang di Bali pada seputaran abad ke-10 juga menegaskan adanya sekte Shaiwa Siddhanta dan Sogata. Bukti lainnya juga disebutkan dalam sejumlah prasasti tentang sebutan orang suci, yakni Dang Acarya untuk pendeta Shiwa dan Dang Upadhyaya untuk pendeta Buddha (Suamba, 2007:148-153). Agama Siwa-Buddha masih hidup di Bali sampai saat ini, terutama dengan masih dilaksanakannya upacara yajna yang dipuput oleh Tri Sadhaka, yaitu Siwa, Buddha, dan Bhujangga.

Akhirnya, dengan memperhatikan pelaksanaan kehidupan keberagamaan antara agama Hindu dan Buddha di Bali sangat penting untuk diketahui lebih jauh tentang keberasaan Agama Hindu dan Buddha di Bali.

\section{Pembahasan}

\subsection{Keberadaan Agama Hindu dan Buddha di Bali}

\section{Ajaran Agama Hindu}

Kitab suci agama Hindu adalah Veda. Dari Veda-lah ajaran agama Hindu itu mengalir. Oleh karena dasar dari agama (Hindu) adalah kepercayaan dan keyakinan, maka agama
Hindu memiliki pokok-pokok keimanan yang disebut dengan Panca Sraddha (panca artinya lima, sraddha berarti kepercayaan). Jadi Panca Sraddha berarti lima kepercayaan dalam agama Hindu yang terdiri dari percaya akan adanya Tuhan, Atman, Karmaphala, Reincarnasi dan Moksa. 1).Tuhan (Sanghyang Vidhi) merupakan sumber dari segala yang ada di dunia ini, serta tidak ada yang luput dari kemahakuasaan-Nya. Hal ini dijelaskan dalam kitab Atharwa Veda IV. 16. 2, yang menyatakan bahwa Beliau maha mengetahui, sehingga tidak ada apapun yang yang dapat kita sembunyikan dihadapan-Nya. 2). Atman adalah hidupnya hidup (azas pribadi), yang merupakan percikan dari Brahman (azas alam semesta). Perpaduan atman dengan badan jasmani, menyebabkan atman dipengaruhi dengan sifat-sifat "maya" dengan segala bentuknya, sehingga menyebabkan avidya (terbawa dalam suka dan duka hidup) yang menyebabkan ketidaksempurnaannya. Apabila atman meninggalkan badan, orang akan mati, sehingga tubuhpun hancur kembali keasalnya. Sedangkan atman tidak akan pernah mengalami kematian karena sifatnya yang kekal abadi. 3). Agama Hindu meyakini adanya hasil (akibat) dari segala perbuatan yang disebut dengan karmaphala. Perbuatan yang baik akan mendatangkan hasil yang baik dan sebaliknya. Oleh karena itu orang akan selalu berbuat baik karena akan dapat memberikan kebahagiaan dan ketentraman serta kerahayuan dalam hidupnya. Hal ini dijelaskan dalab kitab Sarasamuscaya 27 yang menyatakan bahwa apa saja yang orang tabur, itulah hasil yang akan ia petik. Jadi cepat atau lambat segala hasil dari perbuatan akan kita terima. 4). Reinkarnasi juga disebut dengan Punarbhawa (Punar artinya lagi atau kembali, dan Bhawa artinya kelahiran). Reinkarnasi sangat tergantung dari perbuatan kita yang terdahulu. Apabila perbuatan kita yang terhaulu baik, maka diyakini ia akan lahir jadi orang yang bahagia, demikian pula sebaiknya. Oleh karena itu, kesempatan lahir sebagai manusia sangatlah utama karena 
dapat menolong dirinya dari kesengsaraan dengan jalan berbuat baik. Hal ini di nyatakan dalam kitab Sarasamuscaya 4 yaitu keutamaan menjadi manusia yang dapat menolong dirinya sendiri dai penderitaan dengan jalan berbuat baik. Jadi kelahiran sebagai manusia harus digunakan dengan sebaik-baiknya untuk meningkatkan hidup kejenjang yang lebih mulia dan luhur. 5). Moksa berarti kelepasan yaitu terlepas dari segala ikatan keduniawian. Moksa adalah tujuan akhir dalam agama Hindu, karena seperti yang dinyatakan dalam kitab Bhagavadgita III. 15 yaitu apabila orang telah mencapai moksa, ia tidak akan lahir lagi ke dunia karena telah mencapai kesempurnaan yang tertinggi. Ia (atman) telah menyatu dengan Brahman sehingga tidak ada apapun yang mengikatnya. Hal ini diibaratkan seperti air sungai yang telah menyatu dengan air laut, maka air sungai akan kehilangan identitasnya. Demikian pula halnya apabila orang telah mencapai moksa akan menyatu dengan Brahman, serta akan mengalami kebahagiaan yang kekal abadi, yang dalam bahasa Kawi disebut dengan 'Suka tan pawali dukha' yaitu kebahagiaan yang tidak disusul oleh penderitaan.

Dalam penyebaran dan perkembangan agama Hindu di Bali, realisasi dari tata pelaksanaannya didasari oleh sumber ajaran kitab-kitab tattva (pengetahuan) khususnya lontar-lontar Sivatattva. Dalam sastra-sastra lontar, Tuhan dipuja sebagai Bhatara Siva, yang sumbernya selalu di jumpai dalam sastrasastra agama. Ajaran seperti ini disebut sebagai ajaran Sivasiddhanta. Ajaran ini memiliki jalinan yang sangat erat dengan ajaran Upanisad (terutama Svetasvatara Upanisad dan Upanisad-upanisad minor), ajaran-ajaran yang berasal dari kitab-kitab Purana, ajaran-ajaran Samkhya, Yoga, Vedanta dan ajaran-ajaran yang berasal dari kitab-kitab Tantra, yang kesemuanya itu mengalir dari kitab Veda. Wujud tata pelaksanaan kehidupan beragama Hindu berbeda-beda antara satu tempat dengan tempat lainnya, akan tetapi hakikatnya,jiwa dan semangatnya adalah sama.

\section{Ajaran Agama Buddha}

Buddha berarti yang sudah dicerahi, adalah sebutan pada tokoh rohani yang sudah menjelma pada bermacam-macam pribadi yang akhirnya menjelma pada pangeran Siddharta putra raja Suddhodana dari kerajaan Sankya. Julukan Buddha diberikan kepada Siddharta karena kesempurnaannya mendalami ajaran Buddha yang kemudian kata Buddha digunakan untuk menyatakan ajarannya.

Dalam perkembangan selanjutnya ajaran Buddha berkembang menjadi suatu agama yang dianut oleh umat manusia diseluruh dunia dengan menyebut Siddharta sebagai tokoh Buddha. Ajaran Buddha yang disebarkan oleh Siddharta sampai di Birma, Muangtai, Nepal, Tibet, Tiongkok, Jepang, dan sampai ke Indonesia.

Ajaran Buddha yang dikembangkan Siddharta dipandang suatu protes terhadap upacara keagamaan yang berlebih-lebihan karena ajarannya menekankan kepada moral yang tinggi. Baginya hidup adalah penderitaan dan nafsu adalah penyebab penderitaan tersebut. Penderitaan itulah yang menimbulkan kelahiran kembali, untuk menghilangkan penderitaan dengan cara meniadakan avidya (ketidak-tahuan) karena jika avidya sudah dihapuskan akan mencapai nirwana (kebebasan).

Ajaran yang dikembangkan antara lain: Pertama, Dharma merupakan doktrin Buddha yang menekankan ajaran kebenaran yang terdiri dari dukha yang artinya bahwa hidup ini adalah menderita; Samudaya yang artinya setiap penderitaan tentu ada sebabnya; Nirodah maksunya adalah penderitaan atau kesengsaraan dapat dihilangkan dengan jalan menghapuskan nafsu keinginan secara sempurna; Marga adalah jalan kelepasan untuk menuju pemadaman penderitaan. Kedua, Karma dan kelahiran, maksudnya adalah 
karma (perbuatan) menyebabkan terjadinya kelahiran. Ketiga Jalan Kelepasan yang merupakan jalan untuk menuju kebebasan yang terdiri dari : Sraddha, ajaran yang menekankan tentang keyakinan pada Buddha, Dharma dan Jemaat; Sila, yang menekankan pada perbuatan baik; Samadi, yang mengutamakan pencerahan pikiran, dan keempat adalah Nirvana yang merupakan tujuan akhir dari kehidupan yaitu suatu suasana yang tidak lagi dipengaruhi oleh penderitaan, tidak ada kematian, tidak ada gangguan, tidak ada keinginan dan suasananya selalu aman serta damai. Jadi ajaran dan filsafat Sang Buddha, harus dipelajari, dipraktekkan, dan yang terpenting disadari oleh intuisi seseorang. Seperti halnya Dhamma yang disamakan dengan sebuah rakit yang memungkinkan seseorang menyebrangi lautan kehidupan.

\subsection{Peranan Buddha dalam mendukung Aktifitas Agama Hindu di Bali 1. Ajaran Buddha dalam literatur Hindu di Bali}

Ajaran Buddha seolah-olah menjadi bagian dari masyarakat Bali khususnya dan Indonesia pada umumnya. Karena Buddha bukan dianggap agama lagi melainkan dianggap sebagai keharusan dalam menjalankan aktivitas religius. Oleh karena menyusupnya ajaran Buddha dalam masyarakat Bali, sehingga tanpa disadari aktivitas sehari-haripun melibatkan ajaran Buddha, hal yang paling kelihatan adalah masuknya ajaran Buddha pada sastra-sastra Hindu dalam bentuk Kekawin (syair) baik sebagai pedoman hidup maupun sebagai bagian dalam ritual Hindu. Sastra dalam bentuk kekawin ini sering dibacakan dalam aktivitas keagamaan di Bali sebagai bagian dari ritual.

Kekawin yang sering dibacakan pada saat ritual di Bali adalah Kekawin Mahabharata, Kekawin Ramayana, Kekawin Arjuna Wiwaha, Kekawin Bharata Yudha dan Kekawin Sutasoma. Kekawin ini dibaca dalam bentuk tembang yang dilagukan mulai dari awal pelaksanaan ritual sampai akhir pelaksanaan ritual. Ajaran Buddha yang paling lengkap terdapat dalam Kekawin Sutasoma. Kekawin Sutasoma seperti yang kutip oleh Kern dan menjadi landasan dari pembuktiannya bahwa ada percampuran antara Siva dan Buddha. Cerita Pangeran Sutasoma mengandung ajaran suci yang dikenal oleh semua penganut Buddha. Ia adalah Bodhisatva yang artinya penganut Buddha yang sempurna dengan tugas memberikan penerangan kepada umat manusia yang masih terbenam dalam kegelapan dan untuk dapat membebaskan manusia dari kesesatan. Adapun isi Kekawin Sutasoma secara singkat sebagai berikut:

Beliau yang disebut Sanghyang Bajrayana dan maha suci, bersemayam dilubuk hati yang paling dalam, menguasai ketiga dunia (alam atas, tengah dan bawah) seperti bulan dan matahari keadaan beliau, tatkala beliau keluar dari pikiran Buddha. Beliau tiada lain adalah sanghyang Brahma, Visnu dan Isvara, yang pada saat jaman kaliyuga, beliau menjelma menjadi Buddha yang akan membasmi segala kejahatan.

Diceritakan sang Prabu Maha Ketu dengan isterinya Dewi Pradnyadari yang beristana di Astina, sedang dilanda kesedihan karena negaranya diserang oleh para raksasa yang sangat sakti, seluruh bala tentaranya tidak mampu menghadapinya. Oleh karena itu, beliau berdua bekehendak agar mempunyai seorang anak sebagai penerus keturunan dan penyelamat negaranya dengan jalan melaksanakan ajaran Buddha dan bersemadi didepan patung Buddha sampai malam yang sunyi. Pada saat itulah datang Sanghyang Boddhi Satva dan memberi tahu bahwa beliau akan menjelma (reinkarnasi) menjadi putranya. Setelah itu beliau dengan gagah keluar dari tempat semedi, karena merasa handal akan mampu menyelamatkan kerajaannya.

Saat kelahiran Sutasoma dunia terasa bergema karena semua para dewa yang ada disorga mengucapkan mantra sebagai pertanda 
sang Buddha sudah reinkarnasi dan diirinngi hujan bunga yang ditaburkan oleh Dewa Indra serta seisi sorga disekitar istana Astina, yang menyebabkan segala penyakit yang diderita oleh rakyat Astina menjadi sembuh seketika tanpa diobati dan semua penjahat menjadi berbuat baik.

Setelah Sutasoma dewasa, kelihatan sangat tampan dan memliki segala macam pengetahuan baik keduniawian maupun kedewataan. Sang raja merasa waspada terhadap pengetahuan yang dimiliki oleh anaknya karena merasa takut anaknya terlalu terlena dalam ilmu pengetahuan dan tidak mau menikah sebagai penerus keturunan. Maka dari itu sang Sutasoma dipanggil menghadap untuk dijelaskan tentang beban yang diemban pada masa yang akan datang yaitu sebagai penerus menjadi raja dan mensejahterakan dunia. Dalam hal ini sang Sutasoma memaparkan tentang keinginannya menjadi seorang pertapa dihutan dan menjelaskan bahwa untuk mensejahterakan dunia bukan saja menjadi seorang raja bahkan melalui keheningan dan kesempurnaan ilahi akan mampu menyelamakan dunia. Segala bujuk rayu yang dilakukan oleh pembesar kerajaan didepan ayahnya tidak mau didengarkan oleh Sutasoma. Maka saat malam telah tiba seisi istana sedang tidur lelap, Sutasoma keluar dari istana melanjutkan keiinginannya. Dari saat inilah Sutasoma melakukan perjalanan sucinya, sehingga berhasil menyebarkan dharma, demi kesejahteraan umat manusia, yang diakhiri dengan kemampuan Sutasoma untuk menyelamatkan negaranya dari serangan musuh.

\section{Aktvitas Buddha dalam Mendukung Kegiatan Ritual Di Bali}

Agama Hindu khususnya di Bali merupakan salah satu agama yang sarat dengan ritual atau upacara agama sebagai suatu aplikasi dari tri kerangka dasar Agama Hindu yakni; Tattva, Etika dan Ritual. Ritual yang dilaksanakan dikelompokkan menjadi lima kelompok besar yang lazim disebut dengan Panca Yajna yang meliputi ; 1). Dewa Yajna (korban suci yang ditujukan kepada Tuhan), 2). Pitra Yajna (korban suci yang ditujukan kepada para leluhur), 3). Rsi Yajna (korban suci yang ditujukan kepada para Rsi), 4). Manusa Yajna (korban suci yang ditujukan kepada manusia), dan 5). Bhuta Yajna (korban suci yang ditujukan kepada para bhuta-kala).

Sebagai umat Hindu Bali kewajiban untuk merealisasikan yajna tersebut merupakan hal yang urgent (mendesak) dan sangat esensial (penting), sebagai bagian dari upaya untuk meningkatkan sradha bhakti kepada Tuhan dan segala manifestasinya. Sehingga tercapai tujuan hidup dalam âgama Hindu adalah "Moksârtham Jagadhitâya ca iti Dharma" yang berarti kelepasan sang diri dan kesejahteraan hidup bersama demikianlah dharma kita. Jagadhita berarti kesejahteraan hidup hidup bersama (jasmani), sedangkan mok ${ }^{o} a$ berarti kelepasan sang diri. Maksudnya terlepas dari segala bentuk ikatan duniawi, agar dapat menyatunya antara Âtman dengan Brahman. Secara lebih rinci tujuan dari âgama Hindu ini dijabarkan dalam konsepsi Catur Purusa Artha. Catur berarti empat, Purusa berarti jiwa atau manusia, dan Artha berarti tujuan hidup. Jadi Catur Purusa Artha berarti empat tujuan hidup manusia yang terdiri dari Dharma, Artha, Kama dan Mok a. Arah dan sasaran pelaksanaan upacara yang diperlihatkan dalam klasifikasi panca yajna tidak hanya ditujukan kepada Tuhan tetapi juga kepada semua mahluk ciptaan-Nya dengan maksud untuk membina keselarasan hubungan baik secara vertikal maupun secara horisontal. Keselarasan hubungan yang dibangun oleh umat Hindu di Bali baik dalam kehidupan di dunia maupun di akhirat melalui sarana ritual atau yajna merupakan suatu indikasi bahwa umat Hindu di Bali, dalam melaksanakan ajaran agama bukan hanya melalui peningkatan 
kualitas iman atau keyakinan, tetapi juga melalui sarana yang bersifat konkrit dalam wujud sarana upakara atau persembahan suci yang dilandasi oleh kesucian pikiran dan ketulusan hati.

Sarana upakara (offering) yang dipergunakan oleh umat Hindu di Bali dalam suatu upacara sarat dengan simbol-simbol keagamaan yang berfungsi sebagai media penghubung antara yang konkrit dan yang abstrak. Oleh karena itu sarana upakara (offering) yang dipergunakan merupakan representasi dari hal-hal yang bersifat abstrak baik pada bhuana alit maupun bhuana agung. Upakara ini berfungsi sebagai media penghubung untuk mewakili kepentingan seorang bhakta dalam berkomunikasi dengan yang abstrak dan bersifat transenden seperti Tuhan beserta segala manifestasi-Nya.

Ritual yang dilaksanakan dalam memuja Tuhan sebagai salah satu kegiatan masyarakat Bali tidak dapat lepas dari tata aturannya. Pelaksanaan ritual dari sejak persiapan hingga pelaksanaannya sikap mental dan disiplin diri dipandang merupakan landasan yang sangat menentukan kwalitas suatu upacara yang akan dipersembahkan. Sebesar-besarnya ritual yang dilaksanakan tidak akan berarti jika tidak dilandasi dengan sikap dan keperibadian yang baik oleh yang melaksanakan ritual. Lontar Dewa Tattva pada bagian awalnya menyebutkan bahwa tata cara orang yang bersiap-siap untuk melaksanakan ritual baik nista (kecil), madia (menengah) maupun utama (besar) harus berlandaskan pada hati yang tulus iklas. Ketiga tingkatan yajna itu hanya berbeda dalam tingkat kuantitas, namun tidak berbeda dalam kwalitas, karena sama-sama dipersembahkan atas dasar bhakti.

Bila disimak secara mendalam hakekat sebuah yajna dalam agama Hindu tidak hanya mengandung dimensi relegi yang melibatkan berbagai komponen seperti; Manggala upacara (pemimpin ritual), Sang Yajamana (pelaksana upacara), peralatan ritual, waktu ritual, dan keyakinan, tetapi dimensi yang tidak kalah pentingnya dalam pelaksanaan ritual adalah dimensi sosialnya yang tercermin dalam persatuan dan kesatuan, semangat kerjasama atau gotong royong (mutual aid) untuk menyelesaikan ritual.

Pelaksanaan ritual tersebut memerlukan tiga orang suci yang dipercaya untuk mengantar ritual yaitu Sulinggih (orang suci) dari Siva, Buddha dan Bhujangga. Jika salah satu tidak hadir dalam pelaksanaan upacara yang dimaksud maka upacara diyakini tidak akan berhasil selesai dengan sempurna. Semenjak Nusa Bali ditaklukkan oleh Gajah Mada, mahapatih Majapahit sekitar tahun 1343, Nusa Bali dipimpin oleh Danghyang Kresna Kapakisan beristana di Samprangan dan kemudian pindah ke Gelgel. Ketika pimpinan di pegang oleh Dalem Watu Renggong sekitar tahun 1472 datang pulalah Danghyang Nirartha mengajarkan agama di Bali. Mungkin semenjak itu pula ajaran agama Siwa dan Buddha dipersatukan, atau harus diketahui kedua-duanya oleh para pendeta, seperti yang dinyatakan sebagai berikut:

"Apan tiwas juga sirang Muni Buddha paksa. Yan tan wruhing para tattwa Siwatwa marga. Mengkang munindra sangapaksa Siwawatwa yoga. Yan tan wruhing parama tatwa jinatwa manda".

Terjemahannya:

"Karena dipandang kurang sempurna juga bila seorang pendeta penganut Buddha, jika tidak tahu akan inti ajaran Siwa. Demikin pula para pendeta penganut Siwa dipandang tidak sempurna jika tidak tahu inti ajaran Buddha" (Sugriwa, 2008: 37).

Dalam kitab suci Sanghyang Kamahayanikan dinyatakan sebagai berikut:

"Sira katiga Bhatara Hyang Buddha ngaranira, sang atitanagatawartamana, tan hana marganira waneh artinemwaken ikang kahyang Buddhan. Jinatwa mantra widhim param, ikang Mahayana ikang mantranaya, ya ta hy alaksatemwaken kasarbwajnyan, ya ta hetu nirar pangguhaken ikang kahyang Buddhan ring boddhimula”. 
Terjemahannya:

"Ketiganya itu adalah Bhatara (guru) penganut Buddha, dari dulu, pertengahan sampai sekarang, tidak ada jalan lainnya untuk mencapai Hyang Buddha. Bukan jalan lain Mahayana itu yang diturut tatkala akan menuju alam nirwana. Teguh olehnya melakukan latihan Mantranaya itu, sehingga dapat berhasil bertemu dengan Hyang Buddha. Demikianlah tinggi pengaruhnya Mantranaya itu" (Sugriwa, 2008: 41).

\section{Menyatunya Agama Hindu dan Buddha di Bali}

Menyatunya Siva dan Buddha di Indonesia sudah dibicarakan pada saat Indonesia dijajah oleh Belanda. Hal ini disebabkan oleh ketertarikannya melihat penomena ritual yang terjadi pada saat itu. Aktivitas yang dilakukan para akhli penelitian Belanda ini ternyata menghasilkan laporan yang luar bisa dibidangnya, yang terbutkti sampai saat ini penelitian tersebut masih digunakan dikalangan ilmiah untuk mengenal Indonesia. Para akhli tersebut seperti : Kern, yang berjudul Over de Vermenging Van Sivaisme en Buddisme op Java; Ensink, dengan judul, Siva-Buddhism in Java and Bali dan Rassers, yang berjudul Siva en Boeddha in den Indischen archipel dan yang lainnya. Dari sinilah awal mula terjadi perdebatan tentang Siva dan Buddha di Indonesia, yang memunculkan bermacammacam istilah seperti pencampuran, pembauran, perpaduan dan paralellism.

Diterimanya Buddha di Bali karena ada kesamaan ajaran antara Siva dan Buddha sebagai acuan dalam hidup beragama. Kesamaan yang paling menonjol adalah ;

\section{a. Nirvana atau Moksa}

Nirvana (istilah Buddha) berarti tidak lahir kembali atau Moksa (kelepasan sang diri) dalam Siva yang merupakan tujuan terakhir dalam hidup ini. Demikianlah orang yang telah mencapai moksa akan menyatu dengan Brahman (Sang Hyang Widhi), serta akan mengalami kebahagiaan yang kekal abadi yaitu kebahagiaan yang tidak disusul oleh penderitaan.

\section{b. Punarbhava/Reincarnation}

Siva dan Buddha sama-sama mengakui bahwa reincarnasi bertalian sangat erat dengan hukum karma (karma phala). Keyakinan akan adanya punarbhawa maka orang harus sadar bahwa, bagaimana kelahirannya yang sekarang itu sangat tergantung dari perbuatannya yang terdahulu. Kalau dahulu melakukan perbuatan yang baik maka diyakini ia akan lahir menjadi orang yang bahagia. Demikian pula sebaliknya, bila ia melakukan perbuatan yang jelek di masa lalu maka diyakini ia akan menderita. Akan tetapi, lahir sebagai manusia sangatlah utama, karena ia dapat menolong dirinya dari kesengsaraan dengan jalan berbuat baik.

\section{c. Hukum Karma/Karmaphala}

Karmaphala yang dimaksudkan oleh Siva dan Buddha adalah hasil dari perbuatan yang dilaksanakan. Oleh karena perbuatan yang baik akan mendatangkan hasil yang baik pula sehingga kita selalu berusaha untuk berbuat yang baik karena akan memberikan kebahagiaan dan ketentraman serta kerahayuan dalam hidup. Karmaphala dapat dibedakan menjadi tiga bagian yaitu Sancita Karmaphala yaitu hasil perbuatan yang terdahulu bisa diterima pada saat sekarang, Prarabda Karmaphala yaitu hasil dari perbuatan sekarang kita nikmati sekarang, dan Kriyamana Karmaphala yaitu hasil dari perbuatan sekarang bisa diterima pada saat yang akan datang

Kepecayaan seperti inilah yang ditanamkan pada masyarakat Bali dalam kehidupan sehariharinya. Sehingga aktivitas yang dilakukan selalu mengacu pada ajaran tersebut yang melahirkan doktrin Tat Tvam Asi (that is you) yang maksudnya adalah jika tak mau disakiti, jangalah menyakiti orang lain, dan sebagainya. Selain penyatuan ajaran, juga terjadi penyatuan aktivitas keagamaan (upacara) yang berdampak semakin kuatnya jalinan antara Siva dan Buddha di Bali. Jadi esensi dari ajaran agama tidak hanya diwacanakan, namun direalisasikan dalam tindakan dan sikap prilaku. 


\section{KESIMPULAN}

1. Menyatunya Siva dan Buddha di Bali menambah kasanah budaya Bali dalam bidang religius.

2. Walaupun terdapat banyak sekte di Bali, tetapi dalam pelaksanaan ritual tetap mengacu pada satu sekte yaitu Siva.

3. Munculnya Buddha di Bali sebagai sekte, tetapi tetap luluh dalam budaya Bali yaitu menggunakan ritualsebagai medium penghubung dengan yang religius, walaupun pada awal munculnya di India sebagai penentang ritual-ritual yang berlebihan.

\section{DAFTAR PUSTAKA}

Djam'annuri, 2000, Agama Kita, Kunia Kalam Semesta \& LESFI, Yogyakarta

Goundriaan T. and Hooykaas C, 1971, Stuti and Stava, Amsterdam-London : NorthHolland Publishing Company.

Griffith Ralph T.H., 1986, The Hymns Of The Rg. Veda, Delhi : Motilal Banarsidass

Kamus Bali-Indonesia,1991, Dinas Pendidikan Dasar Prop.Bali, Denpasar

Mantra, I. B.,1992, Cult Of Siva Buddha, New Delhi, India

Maswinara, I Wayan, 1997, Bhagawadgita, Paramita, Surabaya

Narada Mahathera, Ven, 1996, Sang Buddha dan Ajaran-AjaranNya (bagian II), Yayasan Dhammadipa Arana, Jakarta

Netra, Anak Agung Gde Oka, 1994, Tuntunan Dasar Agama Hindu, Hanuman Sakti, Jakarta

Oka Diputra, dkk., 1996, Kuliah agama Buddha untuk Perguruan Tinggi, YASADARI, Jakarta,
Pemerintah Daerah Tingkat.II Badung,1998, Kekawin Sutasoma, tanpa nama penerbit, Denpasar, Bali

Pudja, G., dan Sugiarto, R., 1982, Sweta Swatara Upanisad, Mayasari, Jakarta

Pudja, G, 1979, Sarasamuscaya, Mayasari, Jakarta

___ 1990, Wedaparikrama, Jakarta : Dharma Sarati

__—_ 1998, Pengantar Agama Hindu III Veda, Surabaya: Paramita

Punyatmadja, I.B. Oka, 1970, Panca Sradha, Parisada Hindu Dharma, Denpasar

Snelling, John, The Buddhist Handbook, Inner Traditions Rochester,Vermont, 1991

Sura, I Gede, dkk., 1994, Agama Hindu (sebuah pengantar), CV. Kayumas Agung,

Denpasar

_- dkk, 1994, Bhuwanakosa, Upada Sastra, Denpasar , 2000, Ketuhanan dalam Agama Hindu di Bali, Cintamani,

Yayasan Dharmopadesa Pusat, Denpasar , 1991, Pengantar Veda dan Upanisad, Sari Sri Sedana, Denpasar , 1982, Transkripsi Lontar Pametelu Bhatara, Denpasar, Kadokbud Bali.

Tim, 1996, Panca Yadnya, Pemerintah Daerah Tingkat. I Bali, Denpasar ,2000, Siwatattwa, Pemerintah Daerah Tingkat I Bali, Denpasar , 1989, Upanisad Upanisad Utama ( Jilid 2), Yayasan Parijata, Jakarta. 